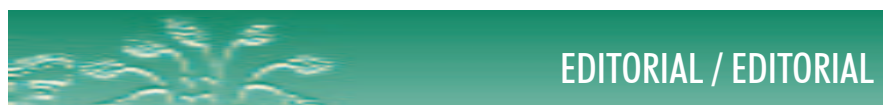

\title{
Quais os núcleos de saberes que conformam o campo da alimentação e nutrição no brasil?
}

What are the cares of knowectgethat shape the field of food and nutrition in brazil?

Esta é uma pergunta que implica assumir que muitas dimensões estão presentes no processo de elaboração de respostas. Em outras palavras, e tomando Bourdieu por referência teórica, cada resposta depende dos agentes em ação no campo, dos interesses em jogo, dos capitais financeiros, científicos e simbólicos acumulados ou em vista, das regras em vigor, das mudanças possíveis que se pode vislumbrar em tempos próximos ou distantes, dos habitus que estruturam e são estruturados em seu interior... Enfim, da dinâmica e da complexidade que se pode tentar compreender nas relações sociais, em particular as relações de poder aí construídas e em construção.

No cenário da ciência e da vida, sempre em transformação, respostas parciais e provisórias dão o tom dos trabalhos, ao mesmo tempo que correspondem à contribuição possível. Buscamos, neste editorial, trazer alguma contribuição a partir do conjunto de artigos publicados em nosso periódico DEMETRA: Alimentação, Nutrição छ̇ Saúde.

Partindo do que respeita ao exercício profissional, o Conselho Federal de Nutricionistas divulgou pesquisa realizada em 2005, na qual destaca a existência de seis "áreas de atuação" no mercado de trabalho. Os resultados relativos à amostra desse estudo encontram-se a seguir. 
Tabela 1. Área de atuação de nutricionistas, Brasil, 2005

\begin{tabular}{lcc}
\multicolumn{1}{c}{ Área de atuação } & Número & Percentual \\
\hline 1. Nutrição Clínica & 1.236 & 41,7 \\
2. Alimentação Coletiva & 963 & 32,2 \\
3. Saúde Coletiva & 262 & 8,8 \\
4. Ensino e Educação & 281 & 9,4 \\
5. Nutrição Esportiva & 122 & 4,1 \\
6. Indústria de Alimentos & 110 & 3,7 \\
\hline Total & $\mathbf{2 . 9 7 4}$ & $\mathbf{1 0 0 , 0}$ \\
\hline
\end{tabular}

Fonte: Conselho Federal de Nutricionistas. Inserção profissional dos nutricionistas no Brasil. Brasília: Conselho Federal de Nutricionistas, 2006. Acesso em 24 de abril de 2013. Disponível em http://www.cfn.org.br/eficiente/ repositorio/Cartilhas/59.pdf.

Outro exercício nesse sentido foi publicado em 2011, a partir de levantamentos relativos a linhas de pesquisa dos programas de pós-graduação inseridos na área de avaliação denominada Nutrição, na CAPES. Na ocasião, foram identificados sete núcleos de saberes, brevemente apresentados abaixo. 
Tabela 2. Núcleos de saberes que conformam o campo científico de Alimentação e Nutrição e sua presença no interior dos programas de pós-graduação stricto sensu inseridos na área de avaliação de Medicina II na Capes, em 2009, no Brasil

\begin{tabular}{|c|c|c|}
\hline Núcleos de saberes & Número* & Percentual \\
\hline 1. Alimentação e Nutrição em Saúde Coletiva & 29 & 42,0 \\
\hline $\begin{array}{l}\text { 1.1. Epidemiologia e Nutrição } \\
\text { (Estudos epidemiológicos sobre nutrição e } \\
\text { determinação do estado nutricional) }\end{array}$ & 14 & 20,3 \\
\hline $\begin{array}{l}\text { 1.2. Políticas de Alimentação e Nutrição } \\
\text { (Estudos sobre políticas, planejamento e gestão de } \\
\text { programas de alimentação e nutrição) }\end{array}$ & 9 & 13,0 \\
\hline $\begin{array}{l}\text { 1.3. Ciências Humanas e Sociais em Alimentação e Nutrição } \\
\text { (Estudos sobre cultura, economia, educação, } \\
\text { comunicação, epistemologia, direito, sociologia, } \\
\text { filosofia em alimentação e nutrição) }\end{array}$ & 6 & 8,7 \\
\hline 2. Nutrição Básica e Clínica & 24 & 34,8 \\
\hline $\begin{array}{l}\text { 2.1. Nutrição Básica } \\
\text { (Estudos bioquímicos, fisiológicos e genéticos sobre } \\
\text { nutrição em animais de laboratório e humanos) }\end{array}$ & 14 & 20,3 \\
\hline $\begin{array}{l}\text { 2.2. Nutrição Clínica } \\
\text { (Estudos clínicos sobre nutrição de humanos) }\end{array}$ & 10 & 14,5 \\
\hline $\begin{array}{l}\text { 3. Nutrição e Alimentos } \\
\text { (Estudos sobre composição química, qualidade sanitária e } \\
\text { tecnologia dos alimentos) }\end{array}$ & 11 & 15,9 \\
\hline $\begin{array}{l}\text { 4. Alimentação e Nutrição em Produção de Refeições } \\
\text { (Estudos sobre produção e consumo de refeições } \\
\text { em Unidades de Alimentação e Nutrição coletivas e } \\
\text { comerciais) }\end{array}$ & 5 & 7,2 \\
\hline Total & 69 & 100,00 \\
\hline
\end{tabular}

Fonte: KAC, Gilberto; PROENCA, Rossana Pacheco da Costa and PRADO, Shirley Donizete. A criação da área "nutrição" na Capes. Rev. Nutr. 2011, v. 24, n. 6, p. 905-916.

* Há duplicidade nos registros acima, pois uma mesma linha de pesquisa, algumas vezes, contempla mais de um dos núcleos de saberes. 
Um importante conjunto de reflexões acerca do campo da Alimentação e Nutrição vem sendo produzido desde a segunda metade do século XX, com destaque para autores como Lucia Ypiranga, Eronides Lima, Maria Lucia Bosi, Francisco de Assis Guedes Vasconcelos, Maria do Carmo Freitas e Ligia Amparo Santos, para citar alguns nomes mais citados. De outro lado, ainda que haja algum registro acerca das áreas de atuação no exercício profissional de nutricionistas ou sobre os núcleos de saberes identificáveis através das linhas de pesquisa dos programas de pós-graduação, praticamente nada há a mais em informações derivadas de investigação científica de cunho descritivo sobre os grupos de pesquisa cadastrados no CNPq, projetos de pesquisa concluídos ou em andamento, dissertações ou teses, publicações, seja na forma de livros ou artigos em periódicos, eventos como congressos ou simpósios que possibilitem ampliar análises sobre a conformação interna do campo da Alimentação e Nutrição no Brasil. Observemos que o campo da Saúde Coletiva tem sido profícuo em relação a essa questão, com muitos artigos e livros publicados e bastante citados na literatura brasileira.

Em face desse certo vazio de informações empíricas, buscamos trazer alguma contribuição aos debates, considerando os artigos publicados em nossa revista DEMETRA. Procedemos a um levantamento dos temas publicados tomando por base a classificação em núcleos de saberes que descreve as linhas de pesquisa dos programas de pós-graduação brasileiros. 
Tabela 3. Temas dos artigos publicados na revista DEMETRA: Alimentação, Nutrição Ė Saúde distribuídos segundo núcleos de saberes que conformam o campo científico de Alimentação e Nutrição de 2006 a 2012

\begin{tabular}{ccc}
\hline \multicolumn{1}{c}{ Núcleos de saberes } & Número* & Percentual \\
\hline $\begin{array}{l}\text { 1. Alimentação e Nutrição em Saúde Coletiva } \\
\text { 1.1. Epidemiologia e Nutrição } \\
\text { (Estudos epidemiológicos sobre nutrição e } \\
\text { determinação do estado nutricional) }\end{array}$ & 34 & $\mathbf{4 6 , 6}$ \\
$\begin{array}{l}\text { 1.2. Políticas de Alimentação e Nutrição } \\
\text { (Estudos sobre políticas, planejamento e gestão de } \\
\text { programas de alimentação e nutrição) }\end{array}$ & 9 & 12,3 \\
$\begin{array}{l}\text { 1.3. Ciências Humanas e Sociais em Alimentação e Nutrição } \\
\text { (Estudos sobre cultura, economia, educação, } \\
\text { comunicação, epistemologia, direito, sociologia, } \\
\text { filosofia em alimentação e nutrição) }\end{array}$ & 15 & \\
\end{tabular}

\section{Nutrição Básica e Clínica}

2.1. Nutrição Básica (Estudos bioquímicos, fisiológicos e genéticos sobre nutrição em animais de laboratório e humanos)

2.2. Nutrição Clínica (Estudos clínicos sobre nutrição de humanos)

3. Nutrição e Alimentos

(Estudos sobre composição química, qualidade sanitária e tecnologia dos alimentos)

4. Alimentação e Nutrição em Produção de Refeições (Estudos sobre produção e consumo de refeições em Unidades de Alimentação e Nutrição coletivas e comerciais)

\section{0}

13

27,4

17,8

7 9,6 6,8 5

* Há duplicidade nos registros acima, pois um mesmo artigo, algumas vezes, pode ser classificado em mais de um dos núcleos de saberes. 
Em primeiro lugar, notemos que o resultado da classificação dos artigos publicados em nosso periódico apresenta perfil bastante distinto daquele identificado para o exercício profissional de nutricionistas, conforme se pode deduzir da comparação entre o que consta das tabelas 1 e 2. O mercado de trabalho segue regras distintas das que se estabelecem no jogo característico dos espaços acadêmicos e, mais ainda, quando o assunto é a pesquisa científica.

Os lugares de inserção profissional que predominam para os nutricionistas são o da Alimentação Coletiva (ou Alimentação e Nutrição em Produção de Refeições) e o da Nutrição Clínica. Tal colocação, quando se dá no setor privado, implica elevadas cargas de tempo de trabalho, o que, praticamente, impede a busca por formação em docência e pesquisa.

Ainda assim, observamos expressiva produção de artigos na nossa revista oriunda do núcleo de saberes que aqui identificamos como Alimentação e Nutrição em Produção de Refeições. São artigos de cunho técnico que, a nosso ver, podem representar esforços em busca de novas posições no campo, talvez por alguma forma de inserção na vida acadêmica - esta tida, possivelmente, como mais prestigiosa, mais bem remunerada e menos pesada. Mulheres tentando acumular capitais financeiros, simbólicos, ainda que a custo de muito esforço extra? Uma possibilidade a ser verificada.

Como periódicos científicos e programas de pós-graduação habitam o mesmo território da formação de pesquisadores e da produção de conhecimentos, encontrar perfis similares entre ambos, como se pode perceber ao comparar as informações que constam das tabelas 2 e 3, leva-nos a pensar que DEMETRA está se mostrando pertinente e inserida no mundo da ciência, podendo corresponder à amostra representativa do que se passa em seu interior. A partir daí, podemos considerar que essa proximidade entre os resultados dos dois levantamentos reforça a perspectiva de que a conformação interna do campo da Alimentação e Nutrição no Brasil pode estar descrita de forma razoavelmente apropriada. Isso sem negar a necessidade premente de outros estudos, inclusive mais específicos a cada um desses núcleos de saberes.

Tomemos, agora, outra classificação que afeta diretamente os jogos de forças, as relações sociais e a distribuição de capitais diversos em todo o campo da Alimentação e Nutrição. Há décadas, o ordenamento interno deste campo foi descrito e institucionalizado por meio da Tabela das Áreas do Conhecimento no CNPq, conforme abaixo: 
Quadro 1. Área Nutrição e suas subáreas na Tabela das Áreas do Conhecimento

\begin{tabular}{|c|c|}
\hline Códigos da Área e das subáreas & Área e subáreas \\
\hline $\mathbf{4 . 0 5 . 0 0 . 0 0 - 4}$ & Nutrição \\
$4.05 .01 .00-0$ & Bioquímica da Nutrição \\
$4.05 .02 .00-7$ & Dietética \\
$4.05 .03 .00-3$ & Análise Nutricional de População \\
$4.05 .04 .00-0$ & Desnutrição e Desenvolvimento Fisiológico \\
\hline
\end{tabular}

Fonte: Conselho Nacional de Desenvolvimento Científico e Tecnológico. Tabela de Áreas do Conhecimento. Acesso em 03 de março de 2012. Disponível em: http://www.cnpq.br/areas/tabconhecimento/index.htm

Essa classificação em áreas e subáreas orienta as ações relativas à estrutura de financiamento e distribuição de recursos (auxílios a pesquisa e bolsas, vagas para estudantes ou docentes no ensino superior e em instituições de pesquisa, por exemplo) em praticamente todas as instituições que operam no âmbito da formação de profissionais e pesquisadores. É o caso de CNPq, CAPES, FINEP, das FAPs e das universidades, para citar as que ocupam a rotina de qualquer pesquisador, docente ou estudante no Brasil.

Registremos que é notória a diferença entre essa classificação por áreas e subáreas e aquela que descreve os núcleos de saberes que orientou a construção das tabelas 2 e 3. Por desdobramento, podemos apresentar a crítica a essa classificação em "áreas do conhecimento", uma vez que ela não mantém correspondência que se sustente com a conformação interna do campo da Alimentação e Nutrição.

As implicações desta distância entre os códigos institucionalizados e a empiria são evidentes e problemáticas: se os pedidos de financiamento dirigidos às agências de fomento à pesquisa seguem obrigatoriamente a classificação vigente, como identificar a que núcleo de saberes corresponde cada pedido de financiamento em face da evidente defasagem entre o que consta da Tabela das Áreas do Conhecimento e o que está descrito a partir das linhas de pesquisa dos programas de pós-graduação ou dos artigos publicados em nossa revista? 
No mínimo, é possível considerar que as chances de sucesso de um pedido de auxílio ou bolsa ficam reduzidas para os que se inserem nos núcleos de saberes não contemplados na Tabela das Áreas do Conhecimento. Afinal, como encaminhar tais propostas para avaliação por pares? Como construir proporcionalidade na distribuição de recursos em face da diversidade ainda tão pouco conhecida? Como distribuir de modo proporcional e adequado os capitais científicos em disputa, se não há representação de cada um dos núcleos de saberes existentes?

Entendemos que é necessário e urgente reconhecer que as regras desse jogo estão defasadas e que a dinâmica atual do campo coloca em ação novos agentes que demandam novos ordenamentos institucionais. O campo da Alimentação e Nutrição necessita que mudanças sejam operadas no âmbito das agências de fomento, e uma delas diz respeito à atualização da Tabela das Áreas do Conhecimento.

DEMETRA coloca assim sua contribuição.

Shirley Donizete Prado 